\title{
Taste aversion in rats with lesions in the frontal lobes: No evidence for interoceptive agnosia
}

\author{
I. DIVAC, A. GADE, and R. E. G. WIKMARK \\ Laboratory of Behavioral Physiology, Institute of Neurophysiology, University of Copenhagen, 2100 Copenhagen, Denmark
}

\begin{abstract}
Ablation of either of the two cortical projection areas of the mediodorsal thalamic nucleus, as well as lesions in the region of the neostriatum associated with the anteromedial cortex, failed to interfere with formation of taste aversion in rats. The prefrontal cortex and the ablated part of the neostriatum in rats are not necessary for association of external and visceral cues or for modification of behavior on the basis of such association.
\end{abstract}

The prefrontal syndrome includes a variety of disturbances which are difficult to incorporate into a meaningful theory. Nauta (1971) has ventured an integrative concept of frontal-lobe functions, based on a growing knowledge of the connections of the frontal cortex and current notions about the functions of the anatomically assoicated area. In his reinterpretation of the problem of the frontal lobe, Nauta stressed the relations between the prefrontal cortex and various limbic formations and the hypothalamus on one hand, and secondary and tertiary "sensory" cortical regions on the other hand. He suggested in general terms that the prefrontal cortex may constitute a neural substrate for integration of interoceptive and exteroceptive information, thus mediating adaptive response-selection. Some more specific and more testable predictions were derived from this notion: ablation of the prefrontal cortex may produce "anomalous visceral responses," but also "interoceptive agnosia," manifested, for instance, as an impairment of "behavioral anticipation" based on visceroendocrine and motivational responses to the environment.

The taste aversion of rats seems to provide an ideal model for testing Nauta's suggestions. Normal rats will markedly decrease intake of food and liquid with a novel taste or smell if ingestion of this substance has once been followed by sickness (Garcia, McGowan, \& Green, 1972). If a rat shows normal avoidance in this paradigm, one may conclude that it perceives the taste (smell), becomes sick, associates the taste (smell) with sickness, remembers this association until the next exposure to the same substance, and selects its responses accordingly. A disturbance in any of these mechanisms would interfere with the formation of taste aversion.

This report describes acquisition of taste aversion after ablation of either of three regions in the frontal lobes in rats, namely, the anteromedial cortex (which is the projection field of the lateral segment of the mediodorsal thalamic nucleus), the dorsal bank of the rhinal sulcus (which is the recipient of fibers from the medial part of the same nucleus), and the anteromedial part of the neostriatum (which is anatomically, as well as functionally related to the anteromedial cortex and the mediodorsal nucleus (Divac, 1971, 1972; Leonard, 1969). In the rat, both prefrontal areas and the mediodorsal nucleus receive direct projections from the amygdala (Krettek \& Price, 1974). The close relation between the amygdala and the prefrontal cortex is of interest here, since lesions in the amygdala interfered with the acquisition of taste aversion to lithium chloride (McGowan, Hankins, \& Garcia, 1972). The suprarhinal bank projects to the hypothalamus (Domesick, 1969; Leonard, 1969). Taste aversion to cyclophosphamide in rats was impaired after large lateral frontal ablations which were aimed at the taste area but involved also the upper bank of the rhinal sulcus (Braun, Slick, \& Lorden, 1972). Thus, on theoretical, anatomical, and neurobehavioral grounds it was predicted that ablation of the prefrontal cortex will impair acquisition of taste aversion in rats.

\section{METHODS}

\section{Subjects}

Twenty-eight male Wistar rats were housed individually with dry food available ad lib. Eighty days before the beginning of the study, the animals received lesions in the anteromedial cortex $(\mathrm{N}=8)$, the dorsal bank of the rhinal sulcus $(\mathrm{N}=6)$, or the anteromedial region of the neostriatum $(\mathrm{N}=7)$; in the remaining rats only, the skin and galea were cut $(N=7)$. The rats had been tested in acquisition and extinction of barpressing for food (in preparation) and in spontaneous alternation (Divac, Wikmark, \& Gade, 1975). Various measures of activity were also taken (in preparation).

\section{Procedure}

The rats had access to water for 20 min daily (between 4 and 6 p.m.) for 21 days. The amount of water ingested was measured daily. On the 15 th, 18 th, and 21 st days, the water was sweetened with saccharin (1:1000). On the 15 th and 18th days, the rats received intraperitoneally $15 \mathrm{ml} / \mathrm{kg}$ of $.12 \mathrm{M}$ lithium chloride after watering.

\section{Surgery}

All operations were performed under $3.3 \mathrm{ml} / \mathrm{kg}$ of Equithesin injected intraperitoneally. Each rat received also $.5 \mathrm{mg}$ of atropine sulfate and 100,000 units of bicillin. The rats were 

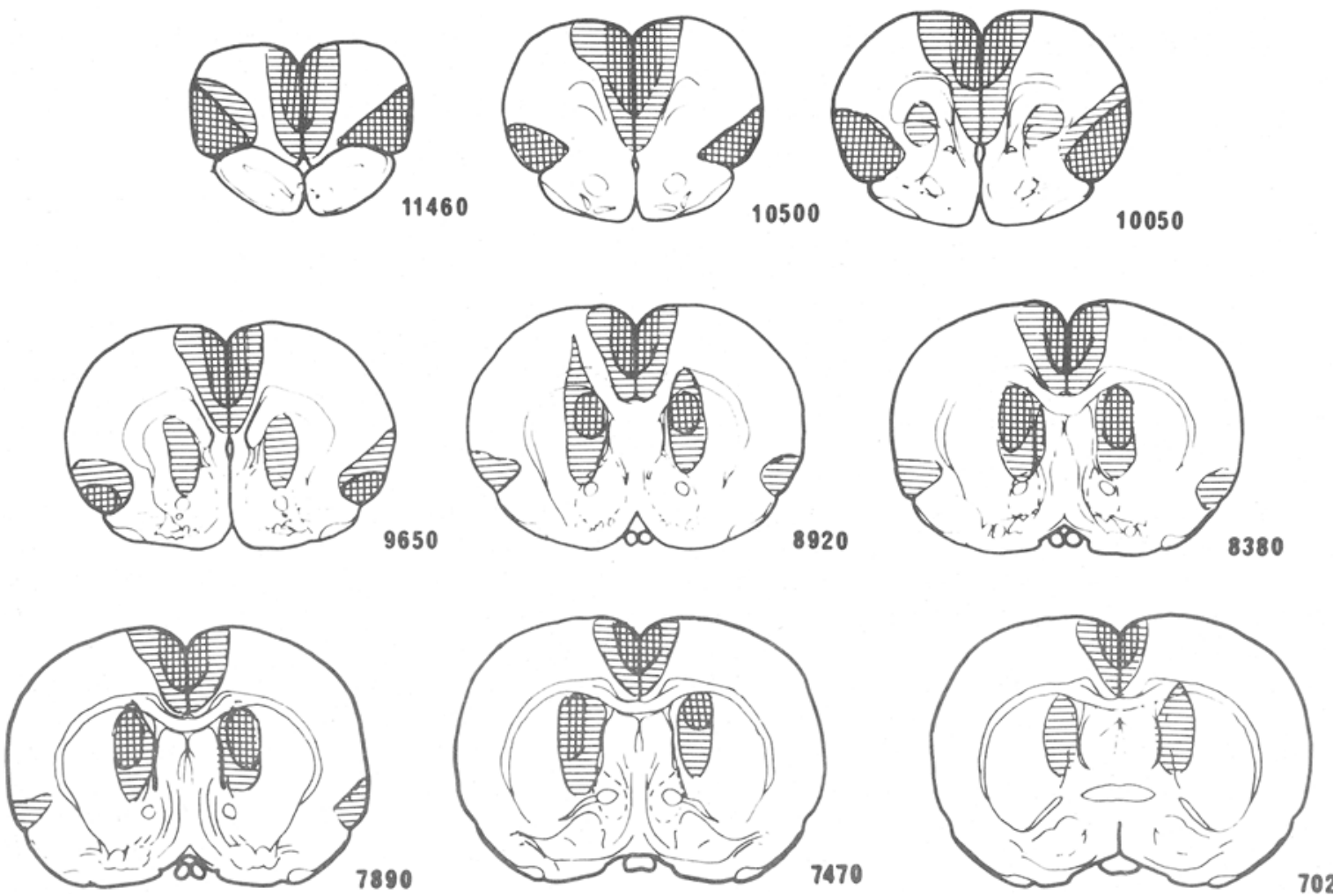

Figure 1. Schematic illustration on standard diagrams of the largest (horizontal stripes) and the smallest (vertical stripes) lesion in each group.

intermittently observed until unprovoked movements began; the mucus was aspirated from the pharynx if difficulties with breathing were observed.

The anteromedial cortex was removed by suction and neostriatal lesions were made electrolytically as described earlier (Wikmark, Divac, \& Weiss, 1973). The upper bank of the rhinal sulcus was ablated after detachment of the temporal muscle and retraction of the skin and the eye anterolaterally. The postero-medial wall of the orbit was thinned by drilling and was removed with watchmaker forceps. A slit in the dura was made with the tip of a hypodermic needle just above the upper edge of the olfactory tract, and the suprarhinal cortex was aspirated along the rhinal fissure with the aid of a dissecting microscope.

\section{Histology}

Deeply anaesthetized animals were transcardially perfused with saline followed by $10 \%$ formalin. The brains were kept in formalin for several days and cut frozen at 100 micra. Every fourth section was mounted, covered, and drawn with the help of a photographic enlarger.

\section{RESULTS}

\section{Anatomy}

The lesions are illustrated in Figure 1. The anteromedial cortical ablations extended to the level of bregma posteriorly. The subcallosal region which does not receive projections from the mediodorsal thalamic nucleus (Leonard, 1969) was spared as intended, whereas the projection area of this nucleus was completely removed in the largest ablations. The following areas were involved in the lesion (Krieg, 1946); the medial part of Area 6 and Area 10, the entire Area 24, most of Area 32, and variable amounts of the anterior part of Areas 4, 23, and 25. In two rats, the corpus callosum and the induseum griseum were damaged. The most extensive ablations of the upper bank of the rhinal sulcus included all of the projection area of the mediodorsal thalamic nucleus as illustrated by Leonard (1969). Krettek and Price (1974) indicated that the lateral cortex above the rhinal sulcus received fibers from the most caudal part of the mediodorsal nucleus. In several of our rats, the superficial layers of this cortex were also damaged. The medial part of the upper bank of the rhinal sulcus which, according to Leonard (1969), does not receive mediodorsal thalamic projections, was, in most cases, left intact. The neostriatal lesions always invaded the overlying white matter. In six rats, the nucleus accumbens septi and, in four cases, the superficial strata of the septum were damaged.

\section{Behavior}

The results were uniform: all rats developed taste aversion. No group of rats with lesions in the frontal lobes differed from the controls in any measure (Kruskal-Wallis one-way analysis of variance). Every brain-damaged animal drank normal amounts of nonsweetened water throughout the experiment, while 
drastically decreasing the intake of saccharin-sweetened water on the second and third exposures. There was no overlap between the volumes of sweetened water ingested by any animal on Days 18 and 21, and the amounts of tap water consumed on any other day. 1

\section{DISCUSSION}

In this study, rats with lesions in the frontal lobes showed no evidence of visceral, motivational, associational, or memory abnormalities. Intact frontal lobes were not necessary for normal regulation of water intake, for perception of taste and sickness, for formation of an association between these temporally separated percepts, or for selection of the adaptive "no-drinking" behavior on the basis of this association after a delay of two days. These results lend no support to Nauta's (1971) suggestion that "interoceptive agnosia" characterizes the frontal-lobe syndrome. Confirmative data may, obviously, be obtained with other parameters, or another paradigm, or other species (e.g., Ursin, Rosvold, \& Vest, 1969). If so, the theory needs to be further specified to yield differential predictions.

The presently established lack of effect of suprarhinal lesions indicates that the abolishment of taste aversion seen after large laterofrontal ablations in rats was due to destruction of the taste area as suggested by Braun et al. (1972). Furthermore, it demonstrates that animals with lesions in the cortical projection field of the medial segment of the mediodorsal thalamic nucleus may be capable of efficient and selective response suppression, of knowing "whether to go" (Rosvold, 1968). The notion of "disinhibition" (Brutowski, 1965), like many other descriptions of the prefrontal syndrome, is to broad.

The development of taste aversion can be regarded as a one-trial passive avoidance conditioning. Ablations of the anteromedial cortex, sparing the subgenual zone, impaired neither avoidance of sickness as studied here, nor passive avoidance of shock (Kaada, Rasmussen, \& Kveim, 1962). Anteromedial lesions which did not invade the pregenual Area 32 of Krieg (1946), left acquisition of conditioned suppression unimpaired (Trafton, 1967). In all these instances, the rats behaved as if expecting discomfort. Thus, impaired "anticipation" (Nauta, 1971) is an unlikely basis for the active avoidance deficit found in rats after anteromedial decortication (Peretz, 1960; Trafton, 1967).

Lesions in the anteromedial region of the neostriatum were as ineffective as the prefrontal ablations in disrupting passive avoidance conditioning as studied here. Caudate lesions are, however, reported to interfere with passive avoidance of shock in rats (Mitcham \& Thomas, 1972; Winocur \& Mills, 1969). There are reasons to believe that deficits in shock-avoidance arise

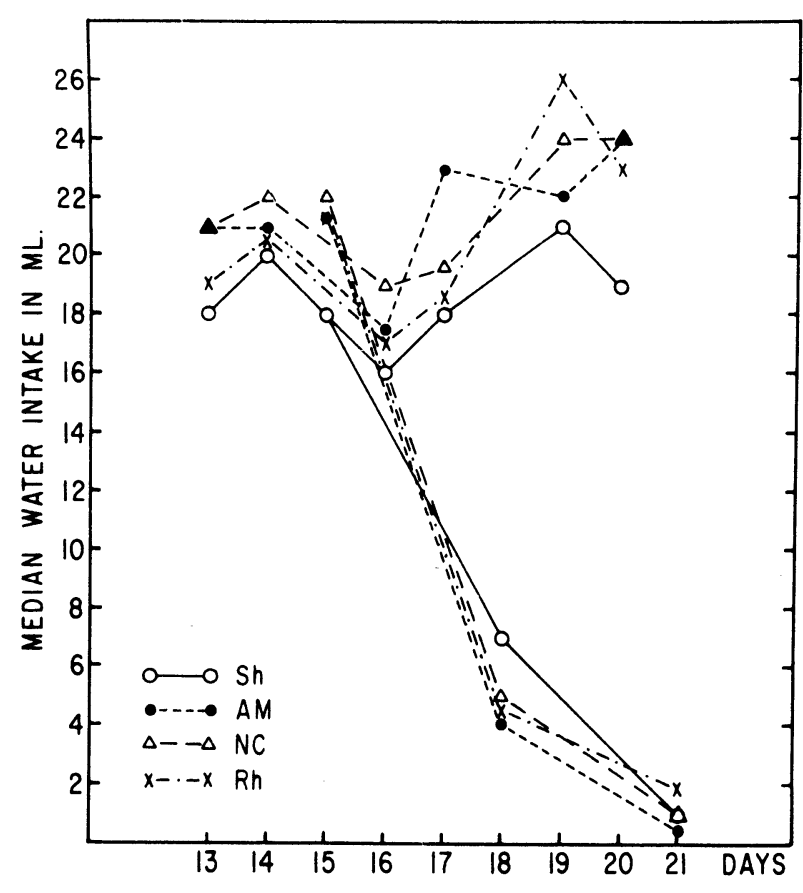

Figure 2. Median water intake for each group on Days 13 through 21. The intake of unsweetened water (Days 13, 14, 16, 17,19 , and 20) is presented separately from the intake of saccharin-sweetened water (Days 15, 18, and 21). Lithium chloride was injected following watering on Days 15 and 18. (Sh: sham operates; Rh: the suprarhinal group; AM: the anteromedial cortical group; NC: the anteromedial neostriatal group.

from injury to some, but not to other, parts of the neostriatum (Thomas \& Hill, 1973; Winocur, 1974). If the caudate nucleus is important for a common process underlying passive avoidance of both pain and sickness, lesions in some parts of the neostriatum would be expected to interfere with the development of taste aversion.

\section{REFERENCES}

Braun, J. J., Slick, T. B., \& Lorden, J. F. Involvement of gustatory neocortex in the learning of taste aversions. Physiology and Behavior, 1972, 9, 637-641.

Brutkowski, S. Functions of prefrontal cortex in animals. Physiological R eview, 1965, 45, 721-746.

Divac, I. Frontal lobe system and spatial reversal in the rat. Neuropsychologia, 1971, 9, 175-183.

Divac, I. Neostriatum and functions of prefrontal cortex. Acta Neurobiologiae Experimentalis. 1972. 32. 461-477.

Divac, I., Wikmark, R. G. E., \& Gade, A. Spontaneous alternation in rats with lesions in the frontal lobes. An extension of the frontal lobe syndrome. Physiological Psychology, 1975, 3, 39-42.

Domesick, V. B. Projections from the cingulate cortex in the rat. Brain Research, 1969, 12, 296-320.

Garcia, J., McGowan, B. K., \& Green, K. F. Biological constraints on conditioning. In A. H. Black and W. F. Prokasy (Eds.), Classical conditioning II. Current research and theory New York: Appleton-Century-Crofts, 1972.

Kaada, B. R., Rasmussen, E. W., \& Kveim, O. Impaired acquisition of passive avoidance behavior of subcallosal, septal, hypothalamic and insular lesions in rats. Journal of 6omparative and Physiological Psychology, 1962, 55,
661-670. 
Krettek, J. E., \& Price, J. L. A direct input from the amygdala to the thalamus and the cerebral cortex. Brain Research, 1974, 67, 169-174.

Krieg, W. J. S. Connections of the cerebral cortex. 1. The albino rat. A. Topography of the cortical areas. Journal of Comparative Neurology, 1946, 84, 221-275.

Leonard, C. M. The prefrontal cortex of the rat. I. Cortical projection of the mediodorsal nucleus. II. Efferent connections, Brain Research, 1969, 12, 321-343.

McGowan, B. K., Hankins, W. G., \& Garcia, J. Limbic lesions and control of the internal and external environment. Behavioral Biology, 1972, 7, 841-852.

Mitcham, J. C., \& Thomas, R. K., Jr. Effects of substantia nigra and caudate nucleus lesions on avoidance learning in rats. Journal of Comparative and Physiological Psychology, 1972, 81, 101-107.

Nauta, W. J. H. The problem of the frontal lobe: A reninterpretation. Journal of Psychiatric Research, 1971, 8, 167-187.

Peretz, E. The effects of lesions of the anterior cingulate cortex on the behavior of the rat. Journal of Comparative and Physiological Psychology, 1960, 53, 540-548.

Rosvold, H. E. The prefrontal cortex and caudate nucleus: A system for effecting correction in response mechanisms. In $\mathbf{C}$. Rupp (Ed.), Mind as tissue. New York: Hoeber, 1968.

Thomas, R. K., \& Hill, H. S. The caudate nucleus and avoidance learning: A reevaluation. Bulletin of Psychonomic Society, $1973,1,346-348$.

Trafton, C. L. Effects of lesions in the septal area and cingulate cortical areas on conditioned suppression of activity and avoidance behavior in rats. Journal of Comparative and Physiological Psychology, 1967, 63, 191-197.
Ursin, H, Rosvold, H, E., \& Vest, B. Food preference in brain lesioned monkeys. Physiology and Behavior, 1969, 4, 609-612.

Wikmark, R. G. E., Divac, I., \& Weiss, R. Delayed alternation in rats with lesions in the frontal lobes: Implications for a comparative neuropsychology of the prefrontal system. Brain, Behavior and Evolution, 1973, 8, 329-339.

Winocur, G. Functional dissociation within the caudate nucleus of rats. Journal of Comparative and Physiological Psychology, $1974,86,432-439$.

Winocur, G., \& Mills, J. A. Effects of caudate lesions on avoidance behavior in rats. Journal of Comparative and Physiological Psychology, 1969, 68, 552-557.

\section{NOTE}

1. These lesions are not always ineffectual. The present rats with anteromedial neocortical or neostriatal damage showed locomotor hyperactivity and deficient extinction of barpressing for food (Gade and Divac, in preparation); the lesions also abolished spontaneous alternation (Divac, Wikmark, \& Gade, Physiological Psychology, 1975). In earlier studies, almost identical lesions impaired spatial reversals (Divac, 1971) and delayed alternation (Wikmark et al., 1973).

(Received for publication September 10, 1974; accepted September 25, 1974.) 